\title{
Vitamin D deficiency in pregnancy and its effects on neonatal outcome
}

\author{
Shweta Gupta, Kanupriya Jain*, Jaspreet Kaur
}

Department of Obstetrics and Gynecology, Dayanand Medical college and Hospital, Ludhiana, Punjab, India

Received: 05 September 2018

Accepted: 28 September 2018

\section{*Correspondence:}

Dr. Kanupriya Jain,

E-mail: kanupj@gmail.com

Copyright: (c) the author(s), publisher and licensee Medip Academy. This is an open-access article distributed under the terms of the Creative Commons Attribution Non-Commercial License, which permits unrestricted non-commercial use, distribution, and reproduction in any medium, provided the original work is properly cited.

\section{ABSTRACT}

Background: India has one of the highest Vitamin D deficiency rates in pregnancy in the world and yet we have limited research to study its various effects from our country. We aim to study the prevalence of Vitamin D deficiency in pregnancy and effect on neonatal outcome after supplementation.

Methods: 200 pregnant women were recruited at 26 weeks and more. They were divided into sufficient group (normal levels of the vitamin), supplemented group (recruited at 26 weeks and supplemented for 8 weeks) and unsupplemented group (recruited after 34 weeks and so could not be supplemented) based on time of recruitment and levels of vitamin D. They were followed up till discharge of newborn from the hospital. Neonatal outcomes were noted.

Results: The prevalence of Vitamin D deficiency in pregnancy in present study was $94.5 \%$. Vegetarians and urban residents were more likely to have this deficiency. Admissions to NICU were significantly less in neonates of vitamin D supplemented women.

Conclusions: The prevalence of vitamin D deficiency is very high during pregnancy and further studies are needed to clearly define its role in neonatal outcome.

Keywords Neonatal outcome, Prevalence, Pregnancy, Vitamin D deficiency

\section{INTRODUCTION}

Vitamin D deficiency is recognized as the most untreated nutritional deficiency currently in world. Vitamin D deficiency is a significant public health problem in both developed and developing countries including India. Although India is a tropical country with abundant sunshine; still vitamin D deficiency is very common in India in all age groups and both sexes across the country. There is growing concern about health consequences of high prevalence of vitamin D deficiency in pregnancy worldwide with upto $50 \%$ of pregnant women classified as vitamin $\mathrm{D}$ deficient. ${ }^{1,2}$ The fetus is dependent on mother for acquiring Vitamin $\mathrm{D}$, as $25(\mathrm{OH}) \mathrm{D}$ readily crosses human placenta. Vitamin D supplementation in pregnancy improves maternal Vitamin D status and may positively affect the availability of Vitamin D to the fetus and neonate. ${ }^{3,4,5}$

There has been paucity of studies evaluating the effects of vitamin D supplementation during pregnancy especially on neonatal outcome. We have attempted to evaluate the prevalence of Vitamin D in pregnancy and the effects of supplementation of this vitamin on neonatal health.

\section{METHODS}

The study was conducted on 200 antenatal women visiting the OPD and emergency of Department of Obstetrics and Gynaecology DMC and Hospital, Ludhiana. 


\section{Inclusion criteria}

- Gestational age at 26 weeks or more.

\section{Exclusion criteria}

- Pregestational diabetes mellitus

- Chronic hypertension

- Renal disease

- Musculoskeletal disorder (congenital or acquired)

- Previous cesarean section

- Known case of hypovitaminosis D

- Women receiving vitamin D.

\section{Methods of collection of data}

The current study was conducted on 200 antenatal women visiting the Emergency and OPD in the Department of Obstetrics and Gynaecology, DMCH, Ludhiana. A detailed history was taken, and clinical examination was done after informed written consent. Spot venous samples for measurement of serum 25hydroxy vitamin $\mathrm{D}$ were taken and analyzed on COBAS 6000 (ROCHE) machine by CHEMILUMINESCENCE method. Reference range of $25(\mathrm{OH}) \mathrm{D}$ according to $\mathrm{DMCH}$, Ludhiana

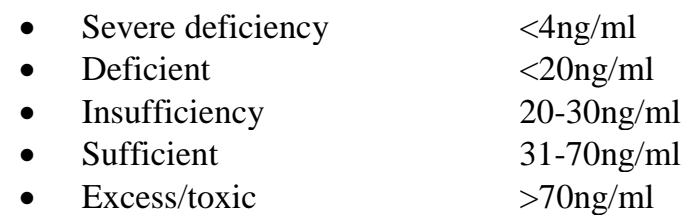

Women were divided into three groups $\mathrm{A}, \mathrm{B}$ and $\mathrm{C}$. Group A included patients with $25(\mathrm{OH}) \mathrm{D}$ levels > 30 $\mathrm{ng} / \mathrm{ml}$ (normal) and group B included patients with 25(OH)D levels <30 ng/ml (Vitamin D deficient). Group $\mathrm{C}$ included women attending the OPD and emergency at 34 weeks of gestation or more with $25(\mathrm{OH}) \mathrm{D}$ levels $<30$ $\mathrm{ng} / \mathrm{ml}$ and with no history of vitamin D supplementation and hence marked as deficient group. Hence prevalence of hypovitaminosis D was studied in the antenatal patients. Standard obstetric care including routine tests and hematinics were offered to all women.

Vitamin D supplementation (Cholecalciferol) at a dose of 60000 IU weekly for 8 weeks and then monthly till delivery was given to Group B. Group B (with supplementation) and group $\mathrm{C}$ (without supplementation) were followed up till delivery and divided into high risk and low risk groups. High risk group included antenatal women with any obstetrical complication like preeclampsia, gestational diabetes mellitus and preterm labour. Low risk group will include antenatal women without any complicating factor. Delivery data was noted. Neonatal characteristics in terms of gestational age at delivery, birth weight and NICU admission were recorded.
Duration of the study: The proposed study was conducted on 200 antenatal women for a period which extends from January $1^{\text {st }}, 2015$ to December $31^{\text {st }}, 2015$.

\section{Statistical analysis}

Statistical analysis was done using Chi square and Student's t-test.

\section{RESULTS}

At enrollment out of total 200 women, 11 (5.50\%) under group A had normal Vitamin D levels, 105 (52.50\%) women were vitamin D Deficient and were supplemented with weekly dose of 60,000 IU vitamin D per orally once a week and then monthly till delivery and 84 (42.00\%) under group $\mathrm{C}$ presented at $\geq 34$ weeks were vitamin $\mathrm{D}$ Deficient and hence could not be supplemented. Out of total 200 women under study 189 were vitamin D deficient at the time of enrollment and hence the prevalence of hypovitaminosis D in pregnancy in present study is $94.5 \%$. Distribution of women in group A, B and $\mathrm{C}$ is detailed in Table 1.

Table 1: Distribution of women in group A, B and C.

\begin{tabular}{|lllll|}
\hline \multirow{2}{*}{ Factors } & & $\begin{array}{c}\text { Group } \\
\text { A }(\%)\end{array}$ & $\begin{array}{l}\text { Group } \\
\text { B (\%) }\end{array}$ & Group \\
\hline \multirow{2}{*}{ Gravidity $(\%)$} \\
\cline { 2 - 5 } & Multigravida & 36.4 & 31.4 & 28.6 \\
\cline { 2 - 5 } $\begin{array}{l}\text { Nutritional } \\
\text { factors }\end{array}$ & $\begin{array}{l}\text { Non- } \\
\text { vegetarian }\end{array}$ & 36.4 & 19.0 & 17.9 \\
\cline { 2 - 5 } & vegetarian & 63.6 & 81.0 & 82.1 \\
\hline \multirow{2}{*}{ Rural/urban } & Rural & 18.2 & 57.1 & 42.9 \\
\cline { 2 - 5 } & Urban & 81.8 & 55.2 & 44.8 \\
\hline
\end{tabular}

The severity of Vitamin D deficiency was also observed as in Table 2. Out of total 189 Vitamin D Deficient women $(\mathrm{B}+\mathrm{C}), 24(12.7 \%)$ had levels less than $4 \mathrm{ng} / \mathrm{ml}$ and hence were severely deficient. 134 (70.9\%) women had levels less than $20 \mathrm{ng} / \mathrm{ml}$ and hence were vitamin D Deficient.

$28(14.8 \%)$ women had vitamin D levels between 20-30 $\mathrm{ng} / \mathrm{ml}$ hence Vitamin D Insufficient. Out of total 24 women with severe Vitamin D deficiency (less than 4 $\mathrm{ng} / \mathrm{ml}), 5(20.8 \%)$ were multigravidas and $19(79.2 \%)$ were primigravidas. The p-value was 0.287 which was not statistically significant.

Out of total 137 women with Vitamin D Deficiency (less than $20 \mathrm{ng} / \mathrm{ml}), 43(31.4 \%)$ were multigravidas and 94 $(68.6 \%)$ were primigravidas. The p-value was 0.550 which was not statistically significant. Out of total 28 women with Vitamin D insufficiency (between 20-30 $\mathrm{ng} / \mathrm{ml}), 9(32.1 \%)$ were multigravidas and $19(67.9 \%)$ were primigravidas. The p-value was 0.804 which was not statistically significant. 
Out of total 24 women with severe vitamin D Deficiency (less than $4 \mathrm{ng} / \mathrm{ml}), 5$ (20.8\%) were non-vegetarians and $19(79.2 \%)$ were vegetarians. The p-value was 0.755 which was not statistically significant. Out of total 137 women with Vitamin D Deficiency (less than $20 \mathrm{ng} / \mathrm{ml}$ ), $26(19.0 \%)$ were non-vegetarians and $111(81.0 \%)$ were vegetarians. The p-value was 0.792 which was not statistically significant.

Table 2: The severity of Vitamin D deficiency.

\begin{tabular}{|llllll|}
\hline Vit D levels & Description & $\begin{array}{l}\text { Group B (sample } 1 \text { before supplementation } \\
\text { between 26-28 weeks) n=105 }\end{array}$ & $\begin{array}{l}\text { Group C (non-supplemented } \\
\text { at } \geq 34 \text { weeks) } \\
\text { n=84 }\end{array}$ \\
\hline Less than 4 & Severely deficient & 10 & $9.5 \%$ & 14 & $16.6 \%$ \\
\hline Less than 20 & Deficient & 78 & $74.3 \%$ & 59 & $70.2 \%$ \\
\hline $20-30$ & Insufficient & 17 & $16.2 \%$ & 11 & $13.1 \%$ \\
\hline
\end{tabular}

Out of total 28 women with vitamin D insufficiency (levels between $20-30 \mathrm{ng} / \mathrm{ml}), 4(14.3 \%)$ were nonvegetarians and $24(85.7 \%)$ were vegetarians. The pvalue was 0.532 which was not statistically significant. Out of total 24 women with severe vitamin D Deficiency (levels less than $4 \mathrm{ng} / \mathrm{ml}), 4$ (16.7) were rural and 20 $(83.3 \%)$ were urban residents. The p-value was 0.803 which was not statistically significant.

Out of total 137 women with vitamin D Deficiency (levels less than $20 \mathrm{ng} / \mathrm{ml}), 24(17.5 \%)$ were rural and $113(82.5 \%)$ were urban residents. The p-value was 0.566 which was not statistically significant. Out of total 28 women with vitamin D insufficiency (levels between 20$30 \mathrm{ng} / \mathrm{ml}), 7(25.0 \%)$ were rural and $21(75.0 \%)$ were urban residents.

The p-value was 0.339 which was not statistically significant. Group A with normal vitamin D levels was followed till delivery, no other high risk was noted (PTLP's, Preeclampsia, GDM) and Neonatal outcome was studied. All $(100 \%)$ the neonates were appropriate for gestational age (AGA) and none were admitted to NICU. In group B (Vitamin D deficient at enrollment and Supplemented) out of total 105, 101 neonates $(96.2 \%)$ were appropriate for gestational age, $1(1 \%)$ was large for gestational age and $3(2.9 \%)$ were small for gestational age.

In group C (Vitamin D deficient at enrollment and NonSupplemented) out of total 84, 76 neonates $(90.5 \%)$ were appropriate for gestational age, $2(2.4 \%)$ were large for gestational age and $6(7.1 \%)$ were small for gestational age. The p-value is 0.278 which is not statistically significant. In group B (Vitamin D deficient at enrollment and Supplemented) out of total 104, $97(92.4 \%)$ were not admitted to NICU and $8(7.6 \%)$ were admitted to NICU for more than 24 hours. In group C (Vitamin D deficient at enrollment and Non-Supplemented) out of total 84, 65 $(77.4 \%)$ were not admitted to NICU and 19 (22.6\%) were admitted to NICU for more than 24 hours. The p-value is 0.003 which is statistically significant.

\section{DISCUSSION}

Various methods were used to assess the Vitamin D status in pregnant women and among the larger studies, ELISA was found to be the most commonly used method.6 Other methods used were RIA and as in present study, the chemiluminescence immunoassay method. The prevalence of hypovitaminosis D in pregnancy in present study is found to be $94.5 \%$. Studies conducted on pregnant mothers in northern and southern states of India from 2005 to 2010 have reported high prevalence of Vitamin D deficiency with values ranging from $67 \%$ to $96 \%{ }^{7}$

We observed vitamin D deficiency in $30.2 \%$ multigravida and $69.8 \%$ in primigravida. In a study in China, nulliparity was found to be a risk factor for Vitamin D Deficiency8. Also, $18.5 \%$ non-vegetarian and $81.5 \%$ vegetarian patients were found to be vitamin $\mathrm{D}$ deficient. Vitamin D deficiency was found to be $18.5 \%$ in rural residents and $81.5 \%$ of urban residents. Vegetarian diet is deficient in Vitamin D so, particularly among individuals with dark skin or with reduced exposure to sunlight it might increase risk of hypovitaminosis D. ${ }^{9-10}$

In present study we observed that after supplementation of 60,000 IU Vitamin D3 or cholecalciferol weekly and then monthly till delivery per orally after 26 weeks of gestation to deficient group, $81 \%$ of women in group B achieved sufficient vitamin $D$ levels ranging between 31 to $70 \mathrm{ng} / \mathrm{ml}$. Cholecalciferol is also available in form of tablets containing $1000 \mathrm{IU}$; or in Injection form (aqueous solution of Vitamin D3 of strength 6 Lac IU). For routine supplementation of pregnant women, sachet containing 60,000 IU of vitamin D3 may be used with added advantage of being non- invasive route of administration. In present study neonatal outcome was studied in terms of weight at birth and it was observed that $96.2 \%$ were AGA, $1.0 \%$ was LGA and $2.9 \%$ neonates were SGA in group B as compared to $90.5 \%, 2.4 \%$ and $7.1 \%$ AGA, LGA and SGA neonates in group $\mathrm{C}$ respectively. 
However, no significant statistical difference was found in both groups(p-0.278). The majority of studies conducted by Morley $\mathrm{R}$ et al, Gale $\mathrm{CR}$ et al and Viljakainen HT et al examining relationships between maternal Vitamin D status and low birth weight found no association. ${ }^{11,12,13}$ An observational cohort study from Boston in 2007 reported no difference in birth weight for gestational age by Vitamin D intake of the mother. ${ }^{14}$ In some other studies, small for gestational age neonate was significantly associated with Vitamin D deficiency in the mother. ${ }^{15,16}$ In present study we also observed that only $7.6 \%$ of neonates were admitted to NICU for more than 24 hours and $92.4 \%$ did not require NICU admission in group B whereas in group C, $22.6 \%$ were admitted to NICU and $77.4 \%$ did not require NICU admission. There was significant statistically significant difference (p0.003 ) between two groups suggesting role of vitamin $\mathrm{D}$ in prevention of neonatal morbidity. We found two studies where neonatal admission to NICU was studied and they found no statistical significance in the difference between the two groups.16,17.

Funding: No funding sources

Conflict of interest: None declared

Ethical approval: The study was approved by the Institutional Ethics Committee

\section{REFERENCES}

1. Hollis BW, Wagner CL, Drezner MK, Binkley NC. Circulating vitamin D3 and 25-hydroxyvitamin D in humans: An important tool to define adequate nutritional vitamin D status. J Steroid Biochem Mol Biol. 2007;103(3-5):631-4.

2. Weisman Y, Harell A, Edelstein S, David M, Spirer Z. 1 alpha, 25-Dihydroxyvitamin D3 and 24,25dihydroxyvitamin D3 in vitro synthesis by human decidua and placenta. Nature. 1979;281(5729):317-9.

3. Delvin EE, Salle BL, Glorieux FH, Adeleine P, David LS. Vitamin D supplementation during pregnancy: effect on neonatal calcium homeostasis. J Pediatr. 1986;109(2):328-34.

4. Yu CK, Sykes L, Sethi M, Teoh TG, Robinson S. Vitamin D deficiency and supplementation during pregnancy. Clin Endocrinol (Oxf). 2009;70(5):68590.

5. Brooke OG, Brown IR, Bone CD, Carter ND, Cleeve HJ, Maxwell JD, et al. Vitamin D supplements in pregnant Asian women: effects on calcium status and fetal growth. Brit Med J. 1980;280(6216):751-4.

6. van der Pligt P, Willcox J, Szymlek-Gay EA, Murray E, Worsley A, Daly RM. Associations of Maternal Vitamin D Deficiency with Pregnancy and Neonatal
Complications in Developing Countries: A Systematic Review.Nutrients.2018;10(5):640

7. Mehlawat U, Singh P, Pande S. Current status of Vitamin-D deficiency in India. IPP. 2014;2(2):32835.

8. Xin Z., Jianping X., Rui F., Renqiang Y., Daozhen C., Jun Z. Maternal vitamin D status in the late second trimester and the risk of severe preeclampsia in southeastern China. Nutrients. 2017;9(2):138

9. Clemens TL, Adams JS, Henderson SL. Increased skin pigment reduces the capacity of skin to synthesise vitamin D3. Lancet. 1982;319(8263):74-6.

10. Harris, S.S. and Dawson-Hughes, B. Seasonal changes in plasma 25-hydroxyvitamin D oncentrations of young American black and white women. Am J Clinic Nutrit. 1998;67(6):1232-6.

11. Morley R, Carlin JB, Pasco JA, Wark JD. Maternal 25-hydroxyvitamin $\mathrm{D}$ and parathyroid hormone concentrations and offspring birth size. J Clinic Endocrinol Metabol. 2006;91(3):906-12.

12. Gale CR, Robinson SM, Harvey NC, Javaid MK, Jiang B, Martyn CN, et al. Maternal vitamin D status during pregnancy and child outcomes. European Journal of Clinical Nutrition. 2008;62(1):68-77.

13. Viljakainen HT, Saarnio E, Hytinantti T, Miettinen M, Surcel H, Makitie O, et al. Maternal vitamin D status determines bone variables in the newborn. J Clinic Endocrinol Metabol. 2010;95(4):1749-57.

14. Camargo CA Jr, Rifas-Shiman SL, Litonjua AA, Rich-Edwards JW, Weiss ST, Gold DR, et al. Maternal intake of vitamin D during pregnancy and risk of recurrent wheeze in children at $3 \mathrm{y}$ of age. Am J Clinic Nutrit. 2007;85(3):788-95.

15. Chen YH, Fu L, Hao JH, Yu Z, Zhu P, Wang H. et al Maternal vitamin D deficiency during pregnancy elevates the risks of small for gestational age and low birth weight infants in Chinese population. J. Clin. Endocrinol. Metab. 2015;100(5):1912-9.

16. Aydogmus S., Kelekci S., Aydogmus H., Eriş S., Desdicioğlu R., Yilmaz B., Sağlam G. High prevalence of vitamin D deficiency among pregnant women in a Turkish population and impact on perinatal outcomes. J. Matern. Fetal Neonatal Med. 2015;28(15):1828-32.

17. Ajmani SN, Paul M, Chauhan P, Ajmani AK, Yadav N. Prevalence of vitamin D deficiency in burka-clad pregnant women in a 450-bedded maternity hospital of Delhi. J Obs Gynecol. India. 2016;66(1):67-71.

Cite this article as: Gupta S, Jain K, Kaur J. Vitamin $\mathrm{D}$ deficiency in pregnancy and its effects on neonatal outcome. Int J Reprod Contracept Obstet Gynecol 2018;7:4481-4. 